\title{
Predictors for gram-negative monomicrobial necrotizing fasciitis in southern Taiwan
}

Tsung-Yu Huang 1,2, Kuo-Ti Peng ${ }^{3,4}$, Cheng-Ting Hsiao ${ }^{5}$, Wen-Chih Fann ${ }^{5}$, Yao-Hung Tsai ${ }^{3}$, Yen-Yao Li ${ }^{3}$, Chien-Hui Hung ${ }^{1,2}$, Fang-Yi Chuang ${ }^{6}$ and Wei-Hsiu Hsu ${ }^{3,4^{*}}$ (D)

\begin{abstract}
Background: Necrotizing fasciitis (NF) is a rare and life-threatening necrotizing skin and soft-tissue infection. Infectious pathogens of NF must be detected early and treated rapidly to prevent loss of limb or a fatal outcome. This study aimed to detect more reliable predictors between gram-negative and gram-positive monomicrobial NF of limbs.

Methods: A total of 100 patients with limb monomicrobial NF were diagnosed prospectively from April 2015 to July 2018. These monomicrobial NF pathogens can be divided into gram-negative and gram-positive groups according to the result of Gram staining and final bacterial reports. Data such as demographics, seawater or seafood contact history, infectious location, comorbidities, presenting signs and symptoms, and laboratory findings were recorded and compared.

Results: A total of 55 patients were infected with gram-negative organisms and 45 patients with gram-positive organisms. Among the 55 cases of monomicrobial gram-negative NF, 48 (87.3\%) were caused mainly by Vibrio spp. $(38,69.1 \%)$ and Aeromonas spp. (10, 18.2\%). A higher incidence of chronic kidney disease, cerebrovascular accident, tachypnea, and septic shock; a higher rate of band forms of leukocytes of more than $3 \%$, serum lactate of more than $20 \mathrm{mg} / \mathrm{dL}$, and C-reactive protein level of less than $150 \mathrm{mg} / \mathrm{dL}$; prolonged prothrombin time; and a lower fibrinogen level were observed in patients with gram-negative infection. In a multivariate analysis, a higher incidence of seawater or seafood contact history (odds ratio [OR]: 66.301; 95\% confidence interval [Cl]: 7.467588.702), a higher rate of hyperlactatemia (OR: 7.904; 95\% Cl: 1.231-50.744), and a low fibrinogen level (OR: 1.013; 95\% Cl: 1.004-1.023) indicated gram-negative infection.

Conclusions: In southern Taiwan, NF of limbs mainly affected the lower limbs, exhibited monomicrobial infection, and was predominated by gram-negative bacteria. Gram-negative monomicrobial NF of limbs often occurred in individuals with the more seawater or seafood contact history, hyperlactatemia, and low fibrinogen levels.
\end{abstract}

Keywords: Fibrinogen, Gram-negative pathogen, Hyperlactatemia, Necrotizing fasciitis, Seafood

\footnotetext{
* Correspondence: 7572@cgmh.org.tw

${ }^{3}$ Department of Orthopedic Surgery, Chang Gung Memorial Hospital, No. 6,

West section, Chia-Pu Road, Pu-Zih city, Chiayi 61363, Taiwan

${ }^{4}$ Department of Medicine, School of Medicine, Chang Gung University, Tao

Yuan, Taiwan

Full list of author information is available at the end of the article
}

(c) The Author(s). 2020 Open Access This article is distributed under the terms of the Creative Commons Attribution 4.0 International License (http://creativecommons.org/licenses/by/4.0/), which permits unrestricted use, distribution, and reproduction in any medium, provided you give appropriate credit to the original author(s) and the source, provide a link to the Creative Commons license, and indicate if changes were made. The Creative Commons Public Domain Dedication waiver (http://creativecommons.org/publicdomain/zero/1.0/) applies to the data made available in this article, unless otherwise stated. 


\section{Background}

Necrotizing fasciitis (NF) is a rare and life-threatening necrotizing skin and soft-tissue infection (NSSTI) characterized by a rapid spread of necrosis in the subcutaneous tissues, particularly the superficial and deep fascia $[1,2]$. Necrotizing fasciitis is associated with high mortality despite patients undergoing aggressive operative debridement and fasciotomy and adequate parenteral antibiotic therapy [2]. The overall amputation rate in NF was 4.7-22.5\% [39], and the mortality rate was $12.1-76 \%$ [2-12]. Early fasciotomy, an appropriate antimicrobial regimen ordered with microbiologic proof, or empiric antimicrobial therapy supported by infectious-disease physicians should be performed in critically ill patients suffering from fulminant NF [13-15] to prevent loss of limb and even death.

Type I NF is a polymicrobial infection [16] that accounts for nearly $53.9-69.2 \%$ of all NF types [3, 4]. However, in Taiwan, the incidence of monomicrobial NF is reportedly 60.4-70.6\% [6, 7, 12]. Chang Gung Memorial HospitalChiayi (CGMH-Chiayi) is a 1300-bed capacity tertiary teaching hospital situated on the western coast of southern Taiwan. Given the location, patients are exposed to occupations related to seawater or raw seafood. In our previous reports, Vibrio spp. and Aeromonas spp. have been regarded as the most important gram-negative bacteria causing NF since 2004 [8, 9, 11-13, 17-22], and Vibrio cholerae non-O1 keratitis [23]. Our team, "Vibrio NSSTIs Treatment and Research (VTR) Group," at CGMH-Chiayi consists of professional medical staff working in various departments, namely, emergency medicine, orthopedic surgery, infectious diseases, intensive care unit, and hyperbaric oxygen treatment center. This group has conducted considerable research focused on comparing Vibrio vulnificus with other different infectious microorganisms, including Aeromonas spp. [13], Vibrio cholerae non-O1 [18], and Staphylococcus aureus (S. aureus) [22].

In southwest Taiwan, Gram-negative aerobic bacteria, such as $V$. vulnificus, A. hydrophila, Klebsiella pneumoniae, and Escherichia coli, were the most frequently isolated microorganisms of NF [6-14, 17-22, 24-26], and they can cause more rapid, fulminant, and deadly NF than gram-positive pathogens $[8,12,27]$. In grampositive aerobic pathogens of NF, $\beta$-hemolytic Streptococcus spp. and $S$. aureus were extremely important microorganisms $[3,4,6-10,12,16,22,27-29]$. In comparing gram-negative with gram-positive aerobic $\mathrm{NF}$, the mortality rates of the former group were generally higher than the latter group (17.1-41.2\% vs. 9.1$30.8 \%)$ [8, 12, 27]. V. vulnificus causes the most rapid fatal NSSTIs, with most patients having died within $48 \mathrm{~h}$ after admission [11, 13, 25]. From 1966 to 2014, the pooled estimate of total mortality rates about $V$. vulnificus NSSTIs from the random-effects meta-analysis was as high as $37.2 \%$ [30]. Aeromonas spp. are another fulminant group of microorganisms associated with high mortality of $26.7-50.0 \%$ for NF [9, 12-14, 20].

Diagnostic delays of NF are related to increased morbidity and mortality [31]. In 2011, we compared the prognostic factors and characteristics of gram-negative and grampositive monomicrobial NF [8]. However, insights into the early detection of more reliable predictors between gramnegative and gram-positive monomicrobial NF are rarely discussed. Thus, we used a simple standard protocol that utilizes demographic data, clinical presentations, and laboratory findings to evaluate the possible pathogens of monomicrobial NF of limbs when patients arrived in the emergency department (ED) within $1 \mathrm{~h}$.

\section{Methods}

\section{Setting and study design}

This is a prospective study performed by the VTR Group at CGMH-Chiayi from April 2015 to July 2018. Between these periods, these patients admitted at the ED and diagnosed with skin and soft-tissue infections were initially enrolled in our study (Fig. 1). Only monomicrobial NF of limbs could be analyzed in the study. It followed the tenets of Declaration of Helsinki. Written consent was obtained before the investigation.

Patients with monomicrobial NF of limbs were enrolled in the study using the following criteria: (1) NF was defined by surgical findings, including the presence of grayish necrotic skin, subcutaneous fat and fascia, no resistance of normally adherent fascia to digital blunt dissection, and a purulent discharge resembling foulsmelling dishwater [8, 17, 24]; (2) Histopathological tissue specimens were obtained to confirm the diagnoses [3, 32]; (3) monomicrobial infection was documented by isolating single pathogenic bacteria from soft-tissue lesions and/or blood collected immediately after the patient's arrival at the ED or during surgery [8, 17]; and (4) such bacteria infected any limb.

\section{Demographic data, clinical presentations, and laboratory findings}

Patients with monomicrobial NF of limbs were divided into gram-negative and gram-positive groups according to the results of Gram staining and final bacterial reports. Data such as demographics, seawater or seafood contact history, location of infection, comorbidities, presenting signs and symptoms, and laboratory findings were recorded and compared.

\section{Statistical analysis}

The predictors for gram-negative monomicrobial NF of limbs were determined using a multivariate logistic regression model. Categorical variables were tested by Fisher's exact test, continuous variables were tested by Student's $t$-test or the Mann-Whitney $U$ test, and a 


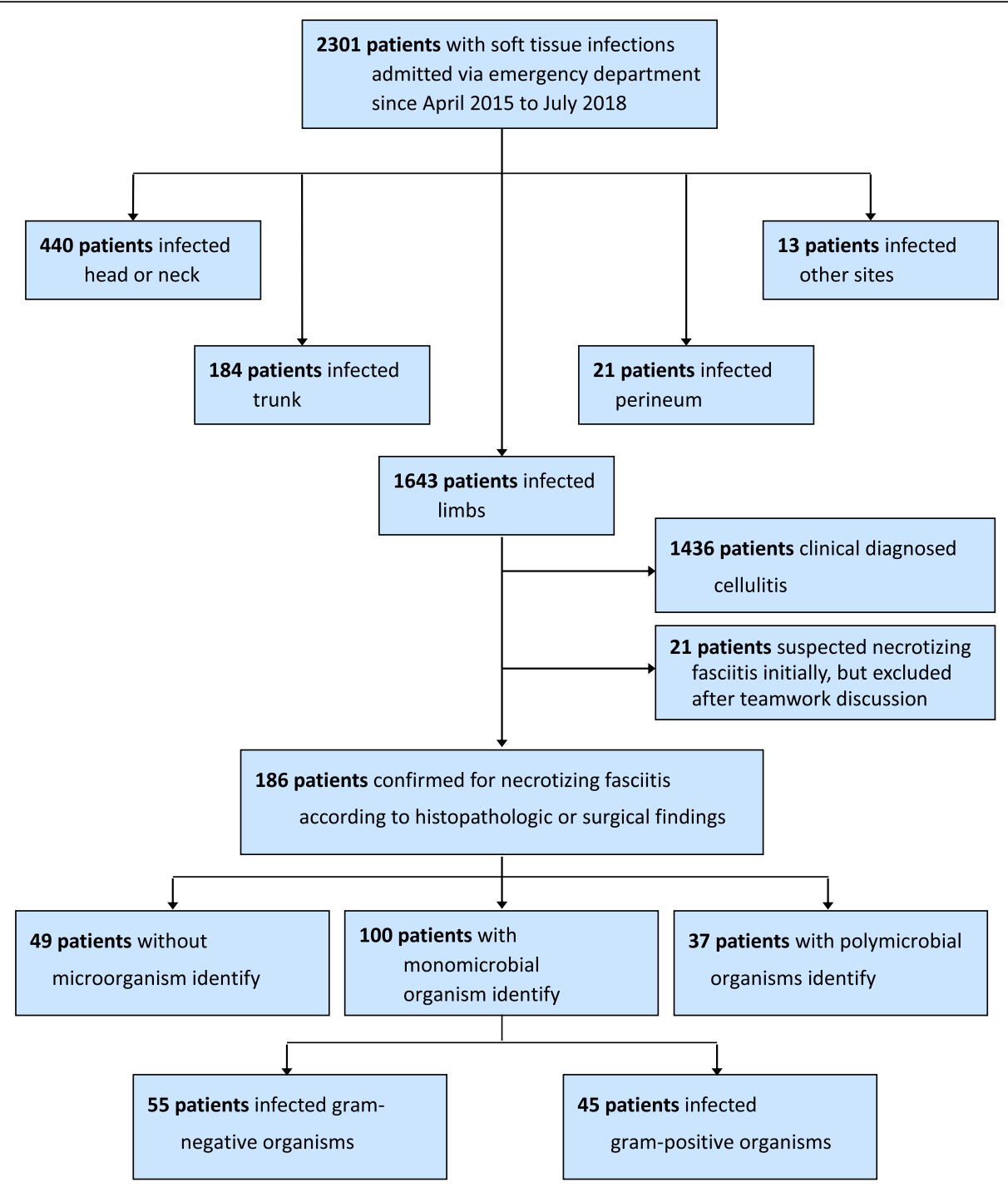

Fig. 1 Flowchart of 100 monomicrobial necrotizing fasciitis

two-tailed $p$-value $<0.05$ was considered statistically significant. Odds ratios (ORs) and 95\% confidence intervals (CIs) were calculated to evaluate the strength of any association, as well as the precision of the estimated effect. All statistical calculations were performed using the Statistical Package for the Social Sciences for Windows, version 18.0 (Chicago, IL, USA).

\section{Results}

\section{Patients and microbiology analysis}

Between April 2015 and July 2018, 186 patients admitted via the ED were surgically confirmed to have NF of limbs (Fig. 1). Among them, 100 (53.8\%) patients had a monomicrobial organism, 37 (19.9\%) had polymicrobial organisms, and 49 (26.3\%) had no microorganism.

The microbiological findings of these 100 monomicrobial NF cases are listed in Table 1. Gram-negative pathogens causing NF were identified in 55 (55\%) patients, whereas gram-positive pathogens were detected in 45 (45\%) patients. V. vulnificus was the most common infectious organism, accounting for 37 (37\%) of the gram-negative bacillary monomicrobial NF cases, followed by the gramnegative organism Aeromonas hydrophila, which was isolated from 9 (9\%) patients. Of the gram-positive cocci, methicillin-resistant $S$. aureus was the most commonly isolated $(15 \%)$, followed by methicillin-sensitive $S$. aureus (13\%) (Table 1).

The gram-negative group had a higher incidence of bacteremia than the gram-positive group $(34 / 55,61.8 \%$ vs. $8 / 45,17.8 \% ; p<0.001)$.

\section{Clinical outcomes}

The gram-negative group had a higher incidence of mortality rate $(9 / 55,16.4 \%$ vs. $3 / 45,6.7 \% ; p=0.138)$ and 
Table 1 Summary of microbiology

\begin{tabular}{ll}
\hline Identified infectious microorganisms & Total No. (\%) \\
\hline Gram-negative pathogens & $55(55)$ \\
Vibrio spp. & $38(38)$ \\
Vibrio vulnificus & 37 \\
Vibrio cholerae non-O1 & 1 \\
Aeromonas spp. & $10(10)$ \\
Aeromonas hydrophila & 9 \\
Aeromonas sobria & 1 \\
Pseudomonas aeruginosa & $2(2)$ \\
Enterobacter cloacae & $2(2)$ \\
Shewanella putrefaciens & $1(1)$ \\
Escherichia coli & $1(1)$ \\
Klebsiella pneumoniae & $1(1)$ \\
Gram-positive pathogens & $45(45)$ \\
Staphylococcus spp. & $30(30)$ \\
MRSA & 15 \\
MSSA &
\end{tabular}

Abbreviations: ${ }^{\mathrm{a}} \mathrm{MRSA}$ Methicillin-resistant Staphylococcus aureus, ${ }^{\mathrm{b}} \mathrm{MSSA}$ Methicillin-sensitive Staphylococcus aureus

amputation rate $(7 / 55,12.7 \%$ vs. $0 / 45,0 \% ; p=0.013)$ than the gram-positive group.

\section{Surgical treatment}

The gram-negative group had a higher number of debridement $(2.05 \pm 1.50$ vs. $1.56 \pm 1.34 \%$; $p=0.085)$, amputation $(0.13 \pm 0.34$ vs. $0 \pm 0 ; p=0.013)$, and fasciotomy $(1.11 \pm 0.42$ vs. $1.04 \pm 0.21 ; p=0.345$ ) than the gram-positive group.

\section{Demographic data}

No significant differences in the parameters of age, gender, and infective regions were observed between these two groups. The gram-negative group was characterized by a higher incidence of seawater or seafood contact history, chronic kidney disease (CKD) and a cerebrovascular accident (CVA) $(p<0.001, p=0.049$, and $p=0.004$, respectively; Table 2). Meanwhile, the gram-positive group was characterized by a higher incidence of gout $(p=0.005$; Table 2).

\section{Clinical presentations}

No significant differences in the presentation of an erythematous, swollen, locally hot, and painful lesion; bulla formation; or skin necrosis were observed between these two groups (Table 3). However, the proportion of patients presenting with tachypnea (respiratory rate $>20$ / min, $43.6 \%$ vs. $11.1 \% ; p<0.001$ ) and shock (systolic blood pressure $<90 \mathrm{mmHg}, 45.5 \%$ vs. $11.1 \%$; $p<0.001$ ) was higher in the gram-negative group than in the gram-positive group (Table 3 ).

\section{Laboratory findings}

No significant differences in total white blood cell count, hemoglobin, platelet count, sodium, creatinine, glucose, total bilirubin, or hypoalbuminemia (serum albumin < $2.5 \mathrm{~g} / \mathrm{dL}$ ) were observed between the two groups (Table 4). The band forms of leukocytes of more than $3 \%$, hyperlactatemia (serum lactate $>20.0 \mathrm{mg} / \mathrm{dL}$ ), and C-reactive protein (CRP) of less than $150 \mathrm{mg} / \mathrm{L}$ were more frequently increased in the gram-negative group $(p=0.030, p<0.001$, and $p<0.001$, respectively; Table 4$)$. In addition, the prothrombin time (PT) values for the gram-negative group were significantly higher than those for the gram-positive group $(p=0.003)$. The proportion of patients presenting with a lower fibrinogen level was frequently observed and significantly higher in the gramnegative group $(p<0.001)$. The gram-positive group had a higher Laboratory Risk Indicator for Necrotizing Fasciitis (LRINEC) score $(\geq 6)$ than the gram-negative group (62.2\% vs. $32.7 \%, p=0.003$; Table 4$)$.

\section{Multivariate analysis}

In a multivariate analysis, a higher incidence of seawater or seafood contact history (OR: 66.301; 95\% CI: 7.467588.702; $p<0.001)$, a higher hyperlactatemia rate (OR: 7.904; 95\% CI: $1.231-50.744 ; p=0.029)$, and a lower fibrinogen level (OR: 1.013; 95\% CI: 1.004-1.023; $p=$ 0.004 ) were indicative of a gram-negative pathogen infection (Table 5).

\section{Discussion}

In our study, 48 (87.3\%) of the 55 patients with monomicrobial gram-negative NF were mainly infected by Vibrio spp. (38, 69.1\%), followed by Aeromonas spp. (10, 18.2\%). From 1988 to 1992, V. vulnificus infection mortality rates had induced $54.2-55.6 \%$ of patients with sepsis [25, 33] and 25.3-35.3\% of patients with soft-tissue infections [25, 33]. Our VTR Group had persistently reduced the mortality rates of Vibrio NF from $38.5 \%$ in 2004 to $13.2 \%$ in $2012[11-13,17-19,22]$ and of $V$. vulnificus NF from $35.3 \%$ in 2007 to $11.1 \%$ in 2012 [12, 13, $18,19,22]$. However, the mortality rate of Aeromonas spp. NF had persistently increased from $26.7 \%$ in 2007 
Table 2 Demographic data from monomicrobial necrotizing fasciitis patients with gram-negative and gram-positive pathogens

\begin{tabular}{|c|c|c|c|}
\hline Variable & Gram-negative pathogen $(n=55)$ & Gram-positive pathogen $(n=45)$ & $P$-value \\
\hline Age (years) & $68.9 \pm 12.9$ & $64.7 \pm 15.4$ & 0.107 \\
\hline Gender, male & $37(67.3)$ & $32(71.1)$ & 0.680 \\
\hline \multicolumn{4}{|l|}{ Involved region } \\
\hline Upper extremities & $23(41.8)$ & $17(37.8)$ & 0.682 \\
\hline Lower extremities & $32(58.2)$ & $28(62.2)$ & 0.682 \\
\hline Seawater or seafood contact history & $38(69.1)$ & $7(15.6)$ & $<0.001^{*}$ \\
\hline \multicolumn{4}{|l|}{ Underlying chronic diseases } \\
\hline Alcoholism & $15(27.3)$ & $12(26.7)$ & 0.946 \\
\hline Chronic kidney disease & $18(32.7)$ & 7 (15.6) & $0.049^{*}$ \\
\hline Cerebrovascular disease & $14(25.5)$ & $2(4.4)$ & $0.004^{*}$ \\
\hline \multicolumn{4}{|l|}{ Chronic liver dysfunction } \\
\hline HBV & $10(18.2)$ & $5(11.1)$ & 0.325 \\
\hline $\mathrm{HCV}$ & $22(40.0)$ & $10(22.2)$ & 0.058 \\
\hline $\mathrm{HBV}$ or HCV & $29(52.7)$ & $15(33.3)$ & 0.052 \\
\hline Liver cirrhosis & $17(30.9)$ & $10(22.2)$ & 0.330 \\
\hline Diabetes Mellitus & $23(41.8)$ & $19(42.2)$ & 0.968 \\
\hline Gout & $0(0)$ & $6(13.3)$ & $0.005^{*}$ \\
\hline Malignancy & $11(20.0)$ & 7 (15.6) & 0.565 \\
\hline Peripheral vascular disease & $0(0)$ & $2(4.4)$ & 0.200 \\
\hline
\end{tabular}

Data was presented as mean (standard deviation) or frequency (\%)

*: $p$-value $<0.05$

to $45.5 \%$ in 2015 [12, 13, 20]. Thus, distinguishing gramnegative from gram-positive NF is extremely important.

Having a higher incidence of seawater or seafood contact history in gram-negative NF is the most important history in our study. Vibrio and Aeromonas spp. are members of the Vibrionaceae family that can thrive in similar aquatic environments. According to past reports, approximately $53.6-100 \%$ of patients with Vibrio infections had a recent history of contact with seawater or raw seafood [11,
17, 18, 25, 33]. Additionally, Aeromonas spp. are often located in fresh or brackish water, sewage, solid, tap water, or nonfecal organic materials [13, 26, 34].

Understanding the demographic findings of patients with NF, especially chronic liver disease (hepatitis or cirrhosis of the liver), chronic alcoholism, CKD, malignant disease, diabetes mellitus, and peripheral vascular disease, is also important $[4,6-8,11,14,21,25,27,33]$. According to previous reports, gouty arthritis was more prevalent in

Table 3 Clinical presentations of patients with gram-negative pathogen and gram-positive pathogen associated monomicrobial necrotizing fasciitis patients

\begin{tabular}{llll}
\hline Variable & Gram-negative pathogen $(n=55)$ & Gram-positive pathogen $(n=45)$ & $P$-value \\
\hline Fever $\left(>38^{\circ} \mathrm{C}\right)$ & $19(34.5)$ & $13(28.9)$ & 0.546 \\
Tachycardia $^{a}$ & $32(58.2)$ & $21(46.7)$ & 0.251 \\
Tachypnea $^{b}$ & $24(43.6)$ & $5(11.1)$ & $<0.001^{*}$ \\
Shock $^{c}$ & $25(45.5)$ & $5(11.1)$ & $<0.001^{*}$ \\
Erythema & $51(92.7)$ & $42(93.3)$ & 0.906 \\
Swelling & $51(92.7)$ & $41(91.1)$ & 0.767 \\
Local hot $_{\text {Pain or tenderness }}$ & $48(87.3)$ & $42(93.3)$ & 0.315 \\
Bullous lesions & $55(100)$ & $45(100)$ & 1.000 \\
Skin necrosis & $28(50.9)$ & $14(31.1)$ & 0.066 \\
\hline
\end{tabular}

Data was presented as mean (standard deviation) or frequency (\%)

*: $p$-value $<0.05$

${ }^{a}$ Tachycardia: heart beat $>100 / \mathrm{min},{ }^{b}$ Tachypnea: respiratory rate $>20 / \mathrm{min},{ }^{\text {c }}$ Shock: systolic blood pressure $<90 \mathrm{mmHg}$ 
Table 4 Laboratory findings of patients with monomicrobial necrotizing fasciitis by gram-negative pathogen and gram-positive pathogen

\begin{tabular}{|c|c|c|c|}
\hline Variable & Gram-negative pathogen $(n=55)$ & Gram-positive pathogen $(n=45)$ & $P$-value \\
\hline \multicolumn{4}{|l|}{ Total WBC count } \\
\hline Leukocytosis ( $\geqq 12,000 /$ uL) & $28(50.9)$ & $31(68.9)$ & 0.069 \\
\hline Leukopenia (@ 4000/uL) & $4(7.3)$ & $2(4.4)$ & 0.554 \\
\hline Leukocytosis or Leukopenia & $32(58.2)$ & $33(73.3)$ & 0.114 \\
\hline \multicolumn{4}{|l|}{ Differential count } \\
\hline Band forms $>3 \%$ & $29(52.7)$ & $14(31.1)$ & $0.030^{*}$ \\
\hline Neutrophilia (> 7500/uL) & $38(69.1)$ & $35(77.8)$ & 0.330 \\
\hline Lymphocytopenia (< 1000/uL) & $34(61.8)$ & $23(51.1)$ & 0.282 \\
\hline Hemoglobin $(<10 \mathrm{~g} / \mathrm{dL})$ & $9(16.4)$ & $4(8.9)$ & 0.269 \\
\hline Thrombocytopenia (< $\left.15 \times 10^{4} / \mathrm{uL}\right)$ & $29(52.7)$ & $18(40.0)$ & 0.205 \\
\hline Hypoalbuminemia $(<2.5 \mathrm{~g} / \mathrm{dL})$ & $7(12.7)$ & $1(2.2)$ & 0.054 \\
\hline Hyperlactatemia (> 20 mg/dL) & 35 (63.6) & $7(15.6)$ & $<0.001^{*}$ \\
\hline C-reactive protein $(<150 \mathrm{mg} / \mathrm{L})$ & $40(72.7)$ & $17(37.8)$ & $<0.001^{*}$ \\
\hline Creatinine $(\mu \mathrm{mol} / \mathrm{L})$ & $180.4 \pm 137.2$ & $134.5 \pm 109.7$ & 0.072 \\
\hline D-dimer (mg/L) & $4.3 \pm 6.9$ & $2.6 \pm 5.8$ & 0.222 \\
\hline Fibrinogen (mg/dL) & $316.5 \pm 145.8$ & $517.4 \pm 164.5$ & $<0.001^{*}$ \\
\hline Glucose (mmol/L) & $9.7 \pm 6.4$ & $10.3 \pm 5.2$ & 0.647 \\
\hline Sodium (mmol/L) & $135.5 \pm 3.5$ & $135.0 \pm 3.5$ & 0.544 \\
\hline LRINEC $^{\mathrm{b}}$ score $\geqq 6$ & $18(32.7)$ & $28(62.2)$ & $0.003^{*}$ \\
\hline $\mathrm{PT}^{\mathrm{C}}$ (seconds) & $13.4 \pm 4.9$ & $11.0 \pm 2.0$ & $0.003^{*}$ \\
\hline Total bilirubin (mg/dL) & $1.9 \pm 1.9$ & $1.7 \pm 3.9$ & 0.718 \\
\hline
\end{tabular}

Data was presented as mean (standard deviation) or frequency (\%)

Abbreviations: ${ }^{\mathrm{a}}$ WBC White blood cell, ${ }^{\mathrm{b}}$ LRINEC Laboratory risk indicator for necrotizing fasciitis, ${ }^{\mathrm{C}} P T$ Prothrombin time

*: $p$-value $<0.05$

Table 5 Multivariate regression for gram-negative pathogen from monomicrobial necrotizing fasciitis patients

\begin{tabular}{lll}
\hline & $\mathrm{OR}^{\mathrm{a}}\left(95 \% \mathrm{Cl}^{\mathrm{b}}\right)$ & $P$-value \\
\hline Seawater or seafood contact history & $66.301(7.467-588.702)$ & $<0.001^{*}$ \\
Hyperlactatemia $>20 \mathrm{mg} / \mathrm{dL}$ & $7.904(1.231-50.744)$ & $0.029^{*}$ \\
Low fibrinogen $(\mathrm{mg} / \mathrm{dL})$ & $1.013(1.004-1.023)$ & $0.004^{*}$ \\
C-reactive protein $<150 \mathrm{mg} / \mathrm{L}$ & $0.153(0.013-1.863)$ & 0.141 \\
Tachypnea & $1.273(0.211-7.661)$ & 0.792 \\
Band $>3 \%$ & $0.570(0.084-3.872)$ & 0.565 \\
Shock & $1.490(0.177-12.566)$ & 0.714 \\
Chronic kidney disease & $0.480(0.075-3.052)$ & 0.437 \\
Cerebrovascular disease & $5.601(0.583-53.777)$ & 0.135 \\
PT (seconds) & $0.822(0.550-1.229)$ & 0.339 \\
Gout & - & 0.999 \\
\hline
\end{tabular}

Abbreviations: a ${ }^{\mathrm{O}}$ Odds ratio, ${ }^{\mathrm{b}} \mathrm{Cl}$ Confidence interval

$*$ : $p$-value $<0.05$ gram-positive NF $[8,28]$, and our study conforms to this result (Table 2). Gram-negative monomicrobial NF had more patients with immunocompromized disorders (CKD, diabetes mellitus, liver dysfunction, or malignancy) [8]. Compared with patients with gram-positive infections, those with gram-negative pathogens were characterized by a higher prevalence of chronic liver dysfunction $[8,12]$ and more likely to have a baseline malignancy [27]. We also found that the proportion of chronic liver disease and malignancy in the gram-negative group was higher than that in the gram-positive group, but it was not statistically different. This result may be due to the small number of patients. Meanwhile, patients who had NF with CKD in the gram-negative group had a higher mortality rate than those in the gram-positive group [8]. In addition, patients who had NF with CKD and CVA can easily acquire gramnegative infections (Table 2); however, this result has been less discussed in previous literature. These similar phenomena may lead to vascular sclerosis.

Furthermore, we need to check the major clinical signs and symptoms of patients with NF. Most of these patients presented with erythematous (52.3-100\%) [3, 7-10], swollen (71.1-100\%) [7-10], locally hot (41.1-96.6\%) [3, 7, 10], 
painful or tender (54.7-100\%) [3, 7-10], and bullous lesions (13.3-44.9\%) [3, 7, 10]. In our study, the gram-negative group had a greater proportion of patients with bullous lesions $(50.9 \%$ vs. $31.1 \%)$ than the gram-positive group, but it had no significant statistical difference. Hemorrhagic bullae are an important skin phenomenon of Vibrio infection that generally developed at the time of admission or within $24 \mathrm{~h}$ of hospitalization and became more severe every hour [25]. Approximately $37-46.4 \%$ of Vibrio infections can develop hemorrhagic bulla, especially primary Vibrio septicemia by $37-54.5 \%$ [25, 33] and Vibrio wound infection by $41-60 \%$ [25, 33]. Although bulla formation can be divided into hemorrhagic bullae or clear bullae, distinguishing them is sometimes difficult. Secondary skin lesions were found on $65.1 \%$ of patients with primary Vibrio septicemia [25] and can occur until $48 \mathrm{~h}$ later [21]. Nonetheless, the emergence of hemorrhagic bullae would be considered a feature of Vibrio, but it is not representative of the performance of all gram-negative bacteria. Fever (24.1-52.8\%) [3, 7-10, 12, 14, 19], hypothermia $(10.9-14.3 \%)[8,14]$, tachycardia (39.874.2\%) [3, 9], tachypnea (47.6\%) [14], and shock (12.164.3\%) $[3,7-10,12,14,19]$ were common systemic manifestations of patients with NF. In our past study, patients with gram-negative NF are statistically more likely to have a fever than those with gram-positive NF [12]. In this study, more patients with gram-negative pathogenic infection experienced fever and tachycardia than those with gram-positive pathogenic infection, but no statistical difference was observed. As compared with NF caused by gram-positive pathogens, those with NF caused by gram-negative pathogens tended to have tachypnea and initially presented with septic shock (Table 3). Such results are consistent with those in our past reports $[8,12]$. More patients presented with dyspnea in the gram-negative group than in the gram-positive group, but this result is discussed rarely in previous studies. Furthermore, more patients had circulatory infection in the gram-negative group than in the gram-positive group (61.8\% vs. $17.8 \%)$. This result may be due to the idea that the gram-negative group had more septicemia-related systemic inflammatory response symptoms [35].

Moreover, we need to check specific hematologic and biochemical tests. Gram-negative pathogens are associated with a higher rate of patients with band forms of leukocytes, lymphocytopenia, or thrombocytopenia than gram-negative pathogens $[8,12]$. In our study, the band forms of leukocytes of more than $3 \%$ were more common in the gramnegative group than in the gram-positive group (Table 4). CRP is synthesized primarily by the liver in response to certain proinflammatory cytokines, and it is a protein of acute systemic inflammation, thereby indicating a prime marker of inflammation. CRP is also an important laboratory parameter of the LRINEC score to distinguish NF from other soft-tissue infections; if patients had an LRINEC score greater than 6 or CRP greater than $150 \mathrm{mg} / \mathrm{dL}$, they are diagnosed with NF [36]. However, in our study, $72.7 \%$ of patients with gram-negative NF and $37.8 \%$ of those with gram-positive NF had initial CRP values of less than 150 $\mathrm{mg} / \mathrm{dL}$ on arriving at the ED, and this finding was not reported before. Lower CRP titers can confuse our judgment in diagnosing NF, especially with gram-negative infections. However, CRP can rise several days later and may decline after patients are treated. Monitoring CRP is still important, but it may not be a good tool to diagnose gram-negative NF in our study. Only $46 \%$ of patients in the gram-positive group had an LRINEC score of 6 or greater, whereas 32.7\% was recorded in the gram-negative group (Table 4). Thus, the LRINEC scoring system is not applicable for determining the early management of patients with suspected Vibrio and Aeromonas NF [19], as well as in this study. In patients with NF, hyperlactatemia is independently associated with in-hospital mortality [37]. Hyperlactatemia generally occurs in patients with shock, respiratory failure, or renal failure [38], consistent with our study. Patients with NF caused by gram-negative pathogens tend to have concurrent bacteremia and initially present with septic shock [14]. Meanwhile, fibrinogen is a kind of acute-phase protein, and its blood levels rise in response to systemic inflammation, tissue injury, and certain events. Elevated fibrinogen levels in inflammation, as well as in cancer and other conditions, have been suggested to be the cause of thrombosis and vascular injury that accompany these conditions [39]. In the present study, fibrinogen consumption was faster in the gram-negative group (Table 4) than in the gram-positive group. The possible cause may be that more septicemia cases in the gram-negative group were complicated with severe tissue damage and systemic inflammation.

In a multivariate analysis, we found three important matters related to gram-negative monomicrobial NF: seawater or seafood contact history, hyperlactatemia, and low fibrinogen levels. Gathering a detailed contact history on occupational exposure to warm seawater, trauma, or seafood or freshwater fish ingestion is necessary. If NF is suspected initially, we need to check the fibrinogen and lactate levels. These two blood tests can also reflect gram-negative organisms related to sepsis.

The present study was limited by having only 100 patients in a period of over 3 years and 4 months. Another limitation is that in the present study, patients were diagnosed mainly on the basis of microbial cultures; culture-negative and polymicrobial NF were not analyzed. The third limitation was that we merely compared gram-negative NF with grampositive NF through limb assessment.

\section{Conclusion}

This study demonstrated the following important points: (1) In southern Taiwan, NF of limbs involved mainly the lower extremities, exhibited high monomicrobial infection, and was predominated by gram-negative bacteria; (2) a 
higher incidence of CKD, CVA, tachypnea, and septic shock; a higher rate of band forms of leukocytes of more than $3 \%$ and a CRP level of less than $150 \mathrm{mg} / \mathrm{dL}$; more prolonged PT, more hyperlactatemia cases, and a lower fibrinogen level were observed in patients with gramnegative monomicrobial NF than in patients with grampositive NF; (3) in a multivariate analysis, gram-negative monomicrobial NF of limbs often occurred in individuals with more seawater or seafood contact history, hyperlactatemia, and a low fibrinogen level.

\section{Abbreviations}

CKD: Chronic kidney disease; ED: Emergency department; LRINEC: Laboratory Risk Indicator for Necrotizing Fasciitis; NSSTI: Necrotizing skin and soft-tissue infection

\section{Acknowledgments}

The authors wish to thank Miss Hsing-Jung Li for assistance in English modification.

\section{Authors' contributions}

TYH participated in the design of the study, collected data, performed the statistical analysis and drafted the manuscript. KTP participated in the design of the study and drafting the manuscript. CTH and WCF conceived the study, carried out surgeries, and coordinated the research groups. YHT and YYL participated in the design of the study and assisted in the surgery. $\mathrm{CHH}$ and FYC participated in the design of the study and revision of the manuscript. WHH participated in the design of the study, statistical analysis and critical review. All authors read and approved the final manuscript.

\section{Funding}

This work was supported in part by grants from Chang Gung Memorial Hospital in Taiwan (Grant No. CORPG6E0051 53). The funding had no role in the design of the study and collection, analysis, and interpretation of data and in writing the manuscript.

\section{Availability of data and materials}

The datasets analyzed during the current study are not publicly available, due to confidentiality reasons, but are available from the corresponding author on reasonable request.

\section{Ethics approval and consent to participate}

This study protocol was approved by the Institutional Review Board of Chang Gung Medical Foundation (Number: 102-5105B). All patients provided written informed consents.

\section{Consent for publication}

Not applicable.

\section{Competing interests}

The authors declare that they have no competing interests.

\section{Author details}

${ }^{1}$ Division of Infectious Diseases, Department of Internal Medicine, Chang Gung Memorial Hospital, Chiayi, Taiwan. ${ }^{2}$ Graduate Institute of Clinical Medical Sciences, College of Medicine, Chang Gung University, Taoyuan, Taiwan. ${ }^{3}$ Department of Orthopedic Surgery, Chang Gung Memorial Hospital, No. 6, West section, Chia-Pu Road, Pu-Zih city, Chiayi 61363, Taiwan. ${ }^{4}$ Department of Medicine, School of Medicine, Chang Gung University, Tao Yuan, Taiwan. ${ }^{5}$ Department of Emergency Medicine, Chang Gung Memorial Hospital, Chiayi, Taiwan. 'Department of Laboratory Medicine, Chang Gung Memorial Hospital, Chiayi, Taiwan.

Received: 26 June 2019 Accepted: 15 January 2020 Published online: 20 January 2020

\section{References}

1. Wilson B. Necrotizing fasciitis. Am Surg. 1952;18(4):416-31.
2. Green RJ, Dafoe DC, Rajin TA. Necrotizing fasciitis. Chest. 1996;110(1):219-29.

3. Wong CH, Chang HC, Pasupathy S, Khin LW, Tan JL, Low CO. Necrotizing fasciitis: clinical presentation, microbiology, and determinants of mortality. J Bone Joint Surg Am. 2003;85-a(8):1454-60.

4. McHenry CR, Piotrowski JJ, Petrinic D, Malangoni MA. Determinants of mortality for necrotizing soft-tissue infections. Ann Surg. 1995;221(5):558-63 discussion 563-555.

5. Ward RG, Walsh MS. Necrotizing fasciitis: 10 years' experience in a district general hospital. Br J Surg. 1991;78(4):488-9.

6. Bair MJ, Chi H, Wang WS, Hsiao YC, Chiang RA, Chang KY. Necrotizing fasciitis in southeast Taiwan: clinical features, microbiology, and prognosis. Int J Infect Dis. 2009;13(2):255-60.

7. Liu YM, Chi CY, Ho MW, Chen CM, Liao WC, Ho CM, Lin PC, Wang JH. Microbiology and factors affecting mortality in necrotizing fasciitis. J Microbiol Immunol Infect. 2005;38(6):430-5.

8. Lee CY, Kuo LT, Peng KT, Hsu WH, Huang TW, Chou YC. Prognostic factors and monomicrobial necrotizing fasciitis: gram-positive versus gram-negative pathogens. BMC Infect Dis. 2011;11:5.

9. Hsiao $C T$, Weng HH, Yuan YD, Chen $C T$, Chen IC. Predictors of mortality in patients with necrotizing fasciitis. Am J Emerg Med. 2008;26(2):170-5.

10. Huang KF, Hung MH, Lin YS, Lu CL, Liu C, Chen CC, Lee YH. Independent predictors of mortality for necrotizing fasciitis: a retrospective analysis in a single institution. J Trauma. 2011;71(2):467-73 discussion 473.

11. Tsai YH, Hsu RW, Huang KC, Chen CH, Cheng CC, Peng KT, Huang TJ. Systemic Vibrio infection presenting as necrotizing fasciitis and sepsis. A series of thirteen cases. J Bone Joint Surg Am. 2004;86-a(11):2497-502.

12. Tsai $Y H$, Huang KC, Shen SH, Hsu WH, Peng KT, Huang TJ. Microbiology and surgical indicators of necrotizing fasciitis in a tertiary hospital of southwest Taiwan. Int J Infect Dis. 2012;16(3):e159-65.

13. Tsai YH, Hsu RW, Huang TJ, Hsu WH, Huang KC, Li YY, Peng KT. Necrotizing soft-tissue infections and sepsis caused by Vibrio vulnificus compared with those caused by Aeromonas species. J Bone Joint Surg Am. 2007;89(3):631-6.

14. Lee CC, Chi CH, Lee NY, Lee HC, Chen CL, Chen PL, Chang CM, Wu CJ, Ko $N Y$, Tsai MC, et al. Necrotizing fasciitis in patients with liver cirrhosis: predominance of monomicrobial Gram-negative bacillary infections. Diagn Microbiol Infect Dis. 2008;62(2):219-25.

15. Huang TY, Hung CH, Lai LJ, Chuang HJ, Wang CC, Lin PT, Hsu WH. Implementation and outcomes of hospital-wide computerized antimicrobial approval system and on-the-spot education in a traumatic intensive care unit in Taiwan. J Microbiol Immunol Infect. 2018;51(5):672-80.

16. Giuliano A, Lewis F Jr, Hadley K, Blaisdell FW. Bacteriology of necrotizing fasciitis. Am J Surg. 1977;134(1):52-7.

17. Huang KC, Hsieh PH, Huang KC, Tsai YH. Vibrio necrotizing soft-tissue infection of the upper extremity: factors predictive of amputation and death. J Inf Secur. 2008;57(4):290-7.

18. Tsai YH, Huang TJ, Hsu RW, Weng YJ, Hsu WH, Huang KC, Peng KT. Necrotizing soft-tissue infections and primary sepsis caused by Vibrio vulnificus and Vibrio cholerae non-01. J Trauma. 2009;66(3):899-905.

19. Tsai YH, Hsu RW, Huang KC, Huang TJ. Laboratory indicators for early detection and surgical treatment of vibrio necrotizing fasciitis. Clin Orthop Relat Res. 2010;468(8):2230-7.

20. Tsai YH, Shen SH, Yang TY, Chen PH, Huang KC, Lee MS. Monomicrobial necrotizing fasciitis caused by Aeromonas hydrophila and Klebsiella pneumoniae. Med Princ Pract. 2015;24(5):416-23.

21. Hsiao CT, Lin L, Shiao CJ, Hsiao KY, Chen IC. Hemorrhagic bullae are not only skin deep. Am J Emerg Med. 2008;26(3):316-9.

22. Tsai YH, Wen-Wei Hsu R, Huang KC, Huang TJ. Comparison of necrotizing fasciitis and sepsis caused by Vibrio vulnificus and Staphylococcus aureus. J Bone Joint Surg Am. 2011;93(3):274-84.

23. Chen WD, Lai LJ, Hsu WH, Huang TY. Vibrio cholerae non-O1 - the first reported case of keratitis in a healthy patient. BMC Infect Dis. 2019;19(1):916.

24. Lee CY, Huang TW, Wu MH, Huang TJ, Li YR, Huang EJ, Tsai YH. Risk factors of synchronous multifocal necrotizing fasciitis: a case control study in comparison with monofocal necrotizing fasciitis in Taiwan. BMC Infect Dis. 2019;19(1):513.

25. Chuang YC, Yuan CY, Liu CY, Lan CK, Huang AH. Vibrio vulnificus infection in Taiwan: report of 28 cases and review of clinical manifestations and treatment. Clin Infect Dis. 1992;15(2):271-6.

26. Ko WC, Chuang YC. Aeromonas bacteremia: review of 59 episodes. Clin Infect Dis. 1995;20(5):1298-304.

27. Yahav D, Duskin-Bitan H, Eliakim-Raz N, Ben-Zvi H, Shaked H, Goldberg E, Bishara J. Monomicrobial necrotizing fasciitis in a single center: the 
emergence of Gram-negative bacteria as a common pathogen. Int J Infect Dis. 2014;28:13-6.

28. Yu KH, Ho HH, Chen JY, Luo SF. Gout complicated with necrotizing fasciitis-report of 15 cases. Rheumatology (Oxford). 2004:43(4):518-21.

29. Schröder A, Gerin A, Firth GB, Hoffmann KS, Grieve A, Oetzmann von Sochaczewski C. Correction to: A systematic review of necrotising fasciitis in children from its first description in 1930 to 2018. BMC Infect Dis. 2019;19(1):469.

30. Huang KC, Weng HH, Yang TY, Chang TS, Huang TW, Lee MS. Distribution of fatal Vibrio Vulnificus necrotizing skin and soft-tissue infections: a systematic review and meta-analysis. Medicine (Baltimore). 2016;95(5):e2627.

31. Erichsen Andersson A, Egerod I, Knudsen VE, Fagerdahl AM. Signs, symptoms and diagnosis of necrotizing fasciitis experienced by survivors and family: a qualitative Nordic multi-center study. BMC Infect Dis. 2018; 18(1):429.

32. Bakleh M, Wold LE, Mandrekar JN, Harmsen WS, Dimashkieh HH, Baddour LM. Correlation of histopathologic findings with clinical outcome in necrotizing fasciitis. Clin Infect Dis. 2005:40(3):410-4.

33. Klontz KC, Lieb S, Schreiber M, Janowski HT, Baldy LM, Gunn RA. Syndromes of Vibrio vulnificus infections. Clinical and epidemiologic features in Florida cases, 1981-1987. Ann Intern Med. 1988;109(4):318-23.

34. Wu CJ, Chen PL, Tang HJ, Chen HM, Tseng FC, Shih HI, Hung YP, Chung CH, Ko WC. Incidence of Aeromonas bacteremia in southern Taiwan: vibrio and Salmonella bacteremia as comparators. J Microbiol Immunol Infect. 2014; 47(2):145-8.

35. American College of Chest Physicians/Society of Critical Care Medicine Consensus Conference. Definitions for sepsis and organ failure and guidelines for the use of innovative therapies in sepsis. Crit Care Med. 1992; 20(6):864-74.

36. Wong C-H, Khin L-W, Heng K-S, Tan K-C, Low C-O. The LRINEC (laboratory risk Indicator for necrotizing fasciitis) score: a tool for distinguishing necrotizing fasciitis from other soft tissue infections*. Crit Care Med. 2004; 32(7):1535-41.

37. Chang CP, Fann WC, Wu SR, Lin CN, Hsiao CT. Lactate on emergency department arrival as a predictor of in-hospital mortality in necrotizing fasciitis: a retrospective study. J Orthop Surg Res. 2019;14(1):73.

38. Juneja D, Singh O, Dang R. Admission hyperlactatemia: causes, incidence, and impact on outcome of patients admitted in a general medical intensive care unit. J Crit Care. 2011;26(3):316-20.

39. Davalos D, Akassoglou K. Fibrinogen as a key regulator of inflammation in disease. Semin Immunopathol. 2012;34(1):43-62.

\section{Publisher's Note}

Springer Nature remains neutral with regard to jurisdictional claims in published maps and institutional affiliations.

Ready to submit your research? Choose BMC and benefit from:

- fast, convenient online submission

- thorough peer review by experienced researchers in your field

- rapid publication on acceptance

- support for research data, including large and complex data types

- gold Open Access which fosters wider collaboration and increased citations

- maximum visibility for your research: over $100 \mathrm{M}$ website views per year

At $\mathrm{BMC}$, research is always in progress.

Learn more biomedcentral.com/submissions 